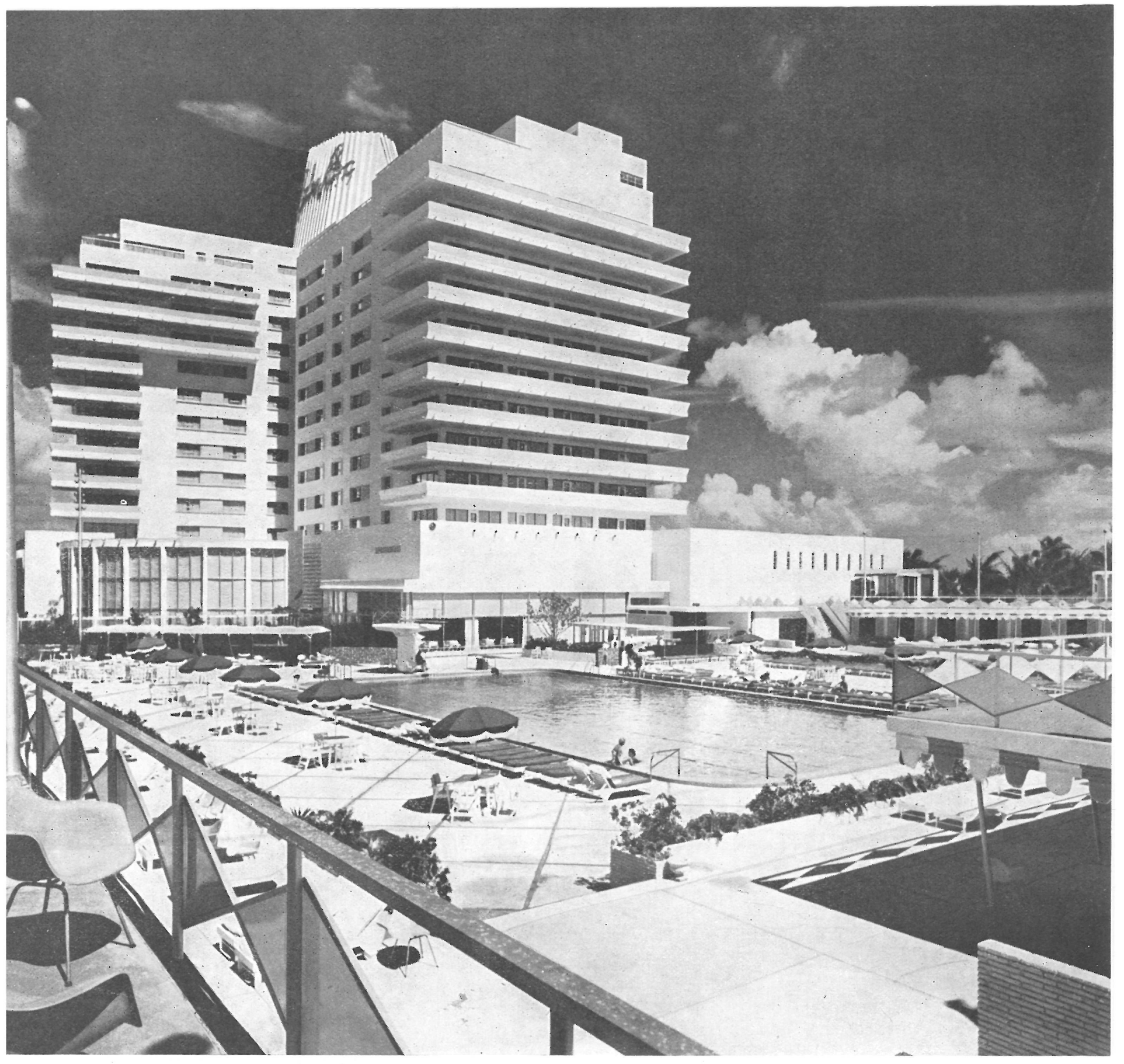

\title{
hotel Eden Roc
}

MORRIS LAPIDUS, arquitecto 


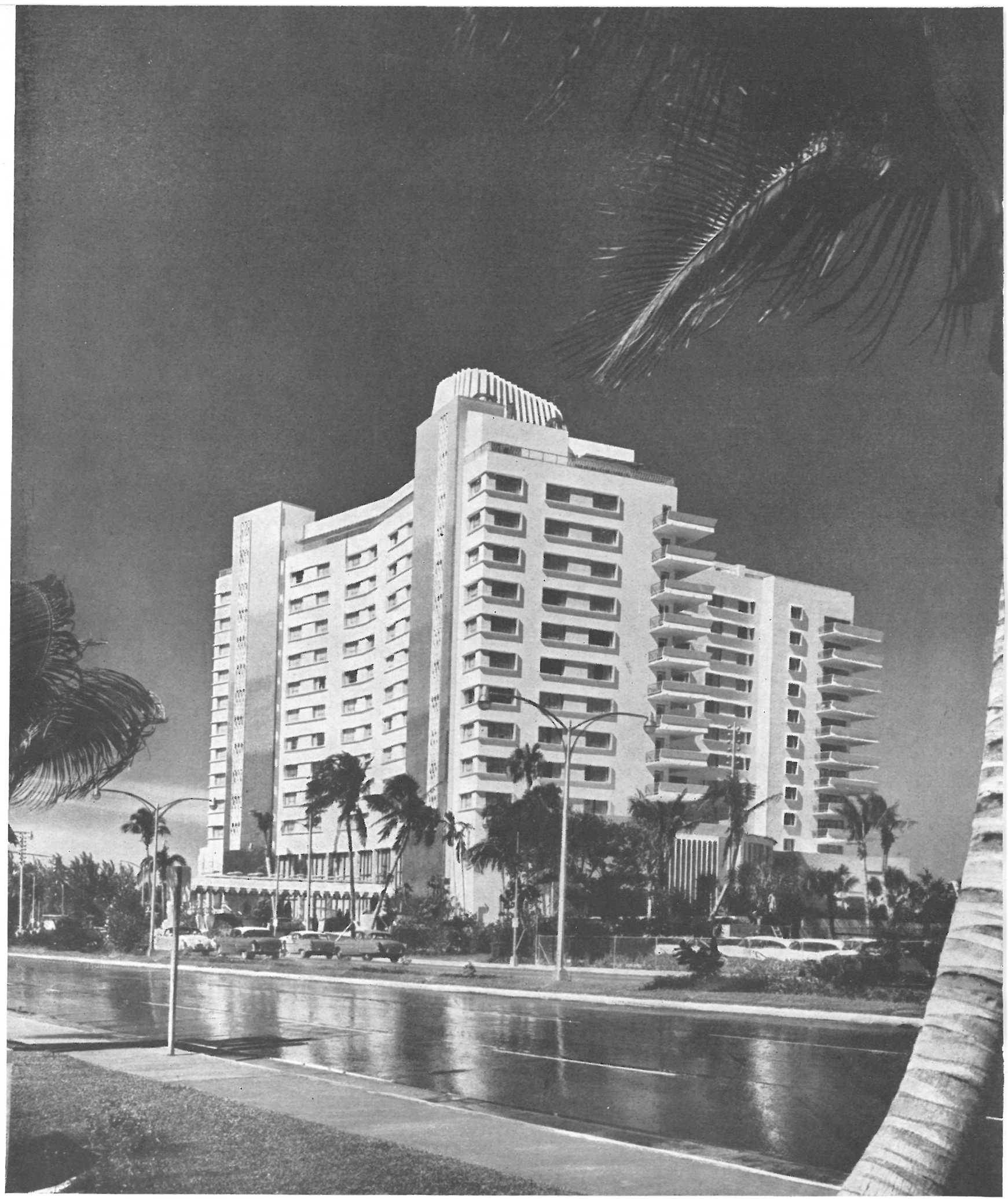

Las playas de Miami son uno de los centros de diversión más importantes de los Estados Unidos. A lo largo de ellas se multiplican los hoteles, rivalizando para ofrecer a sus clientes confort, comodidades y esparcimientos de todo género. Durante un año se trabajó en la construcción del hotel Eden Roc, uno de los más recientes. Se edificó en un solar de forma rectangular, cuyos lados menores están definidos por la Avenida Collins y el Océano. Si dividimos la parcela por una de sus diagonales, uno de los triángulos, el de base en la Avenida Collins, nos define aproximadamente el espacio ocupado por las construcciones en altura, y el otro, que tiene su base en el Atlántico, la zona de esparcimientos. 


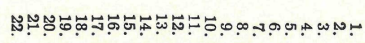

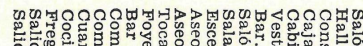

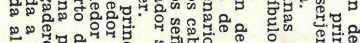

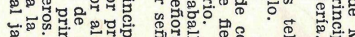

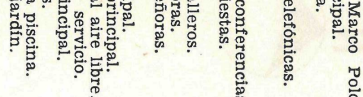

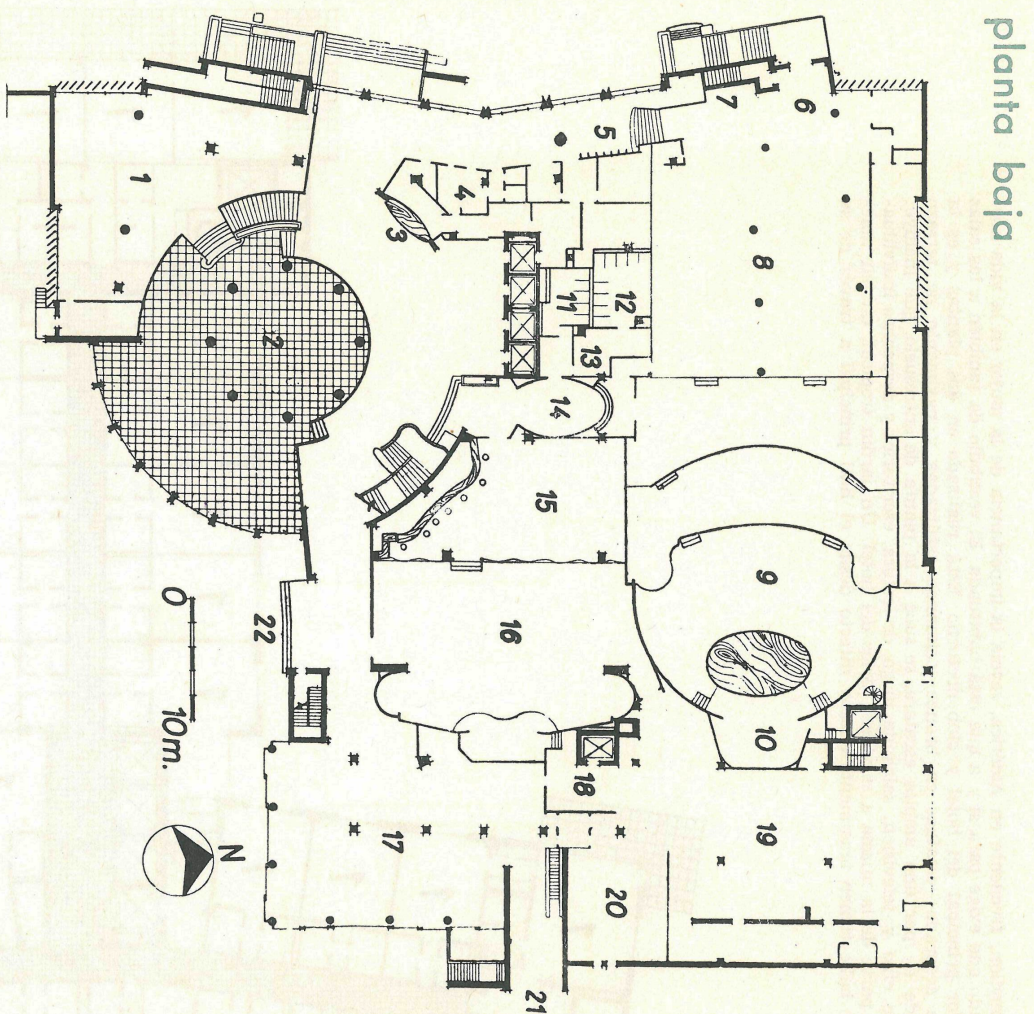

ש.

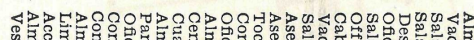

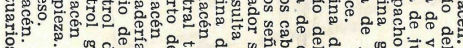

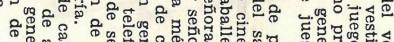

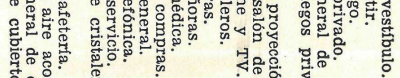

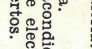
列

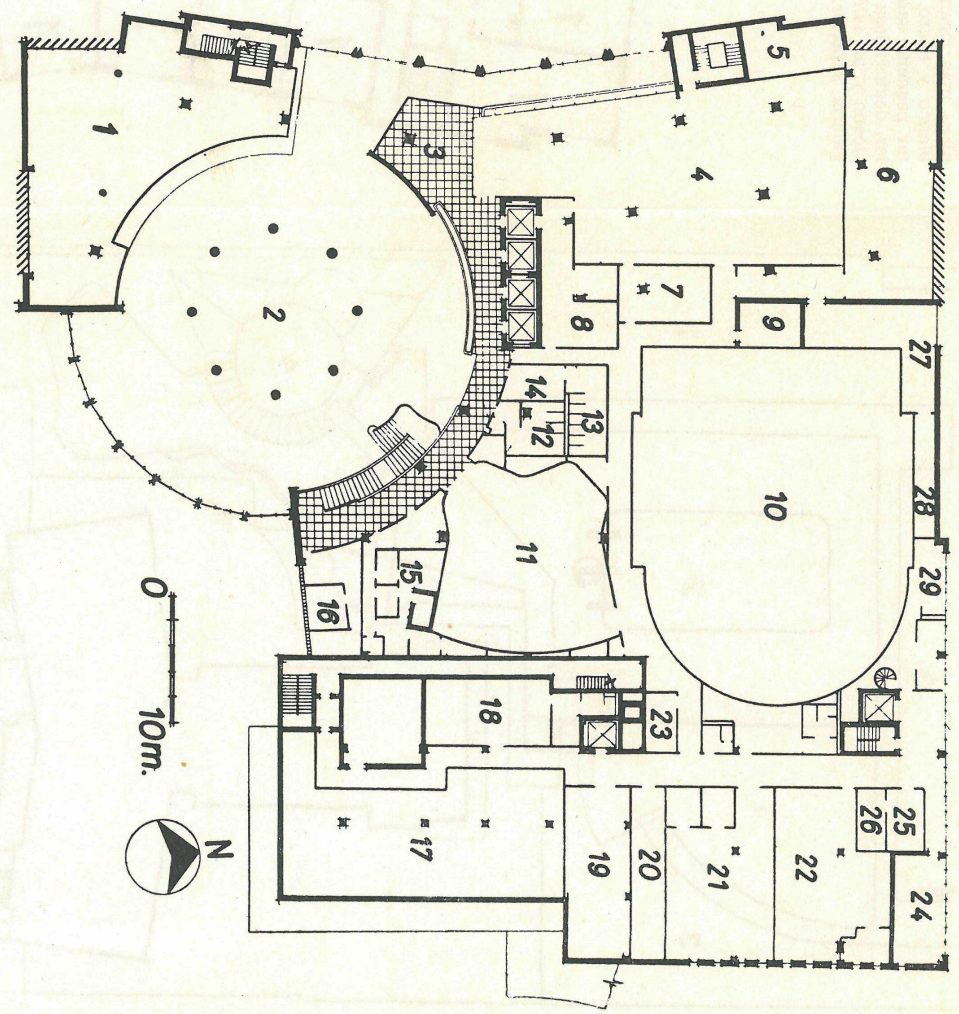



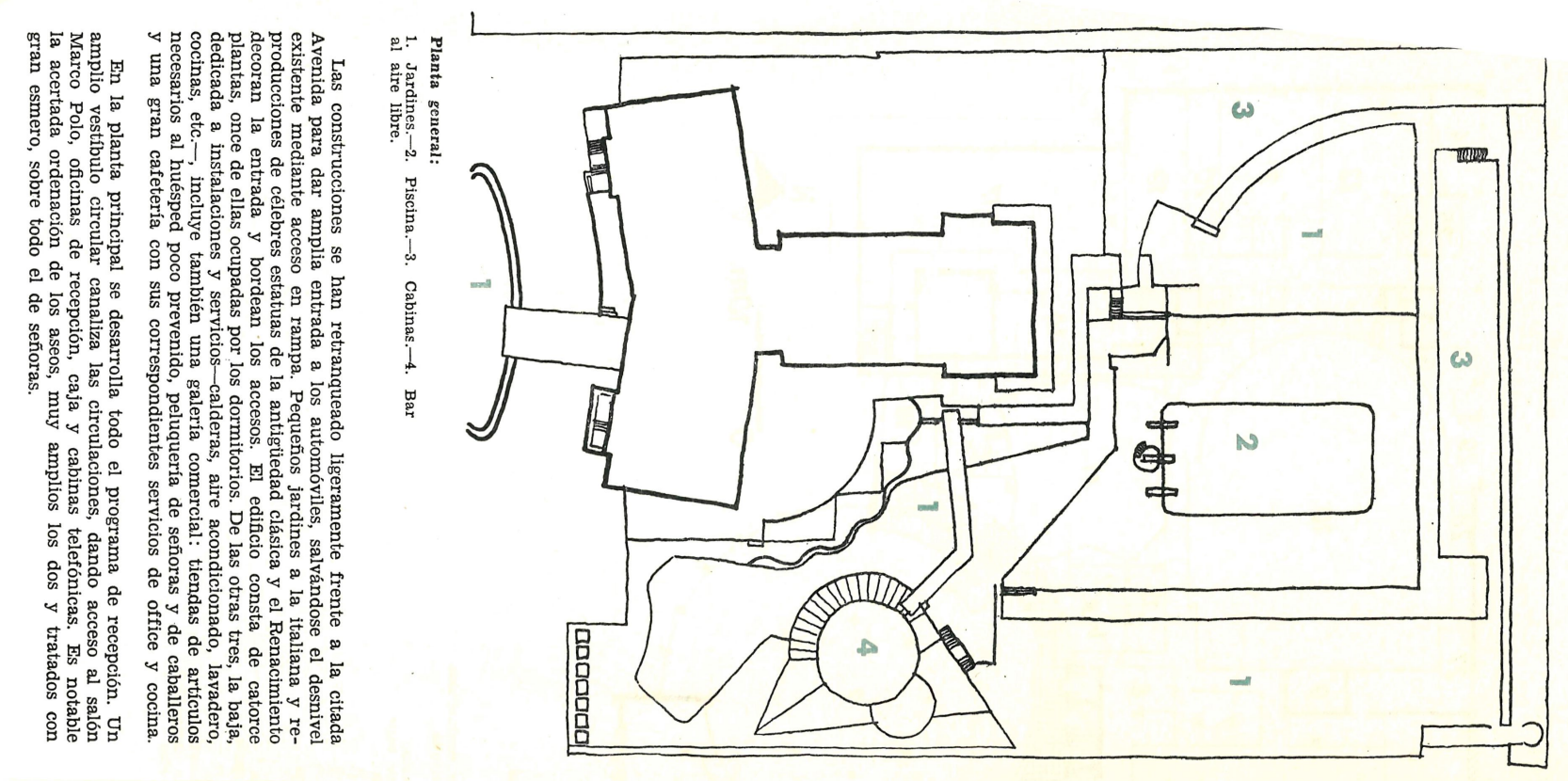

동.
on.
o.
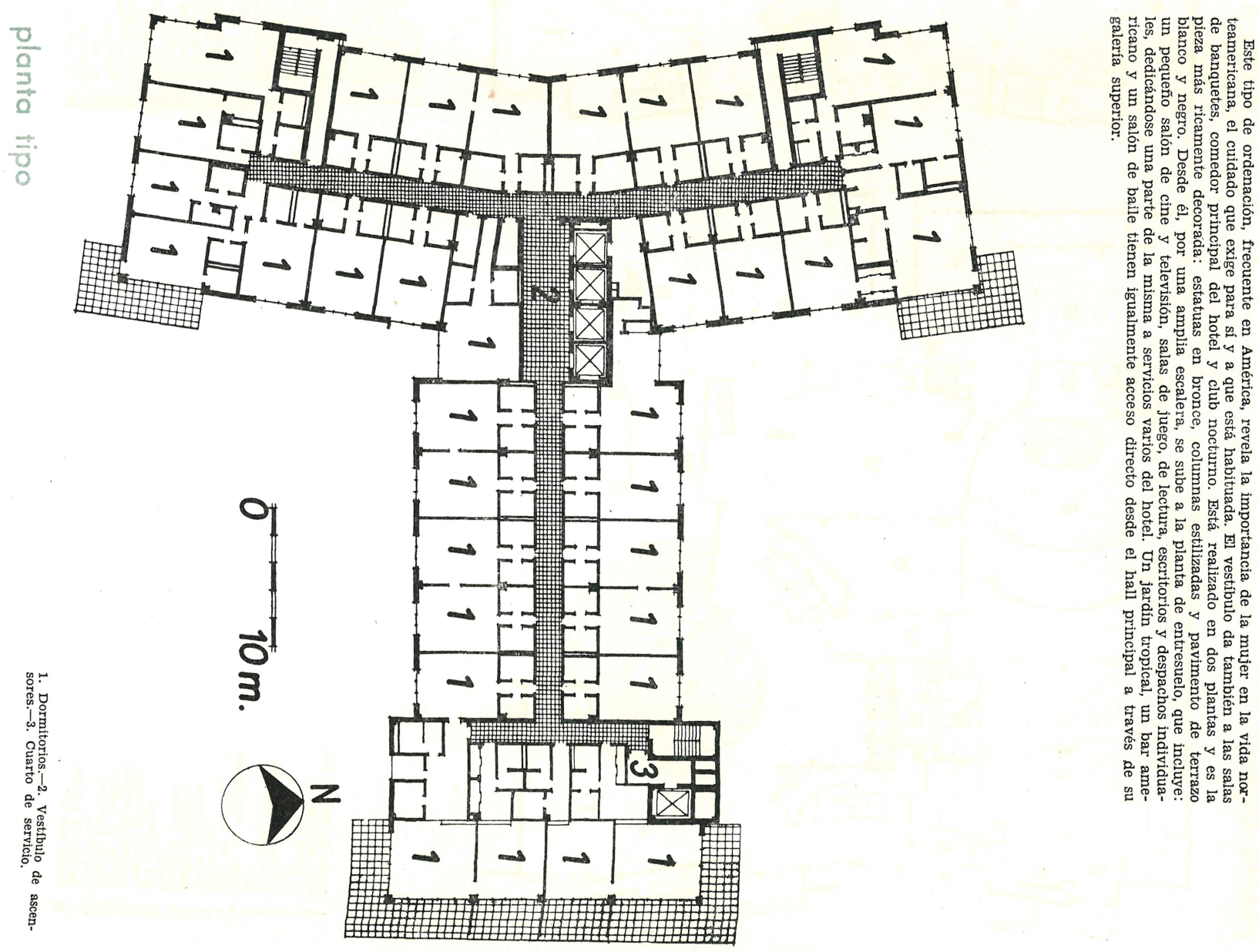


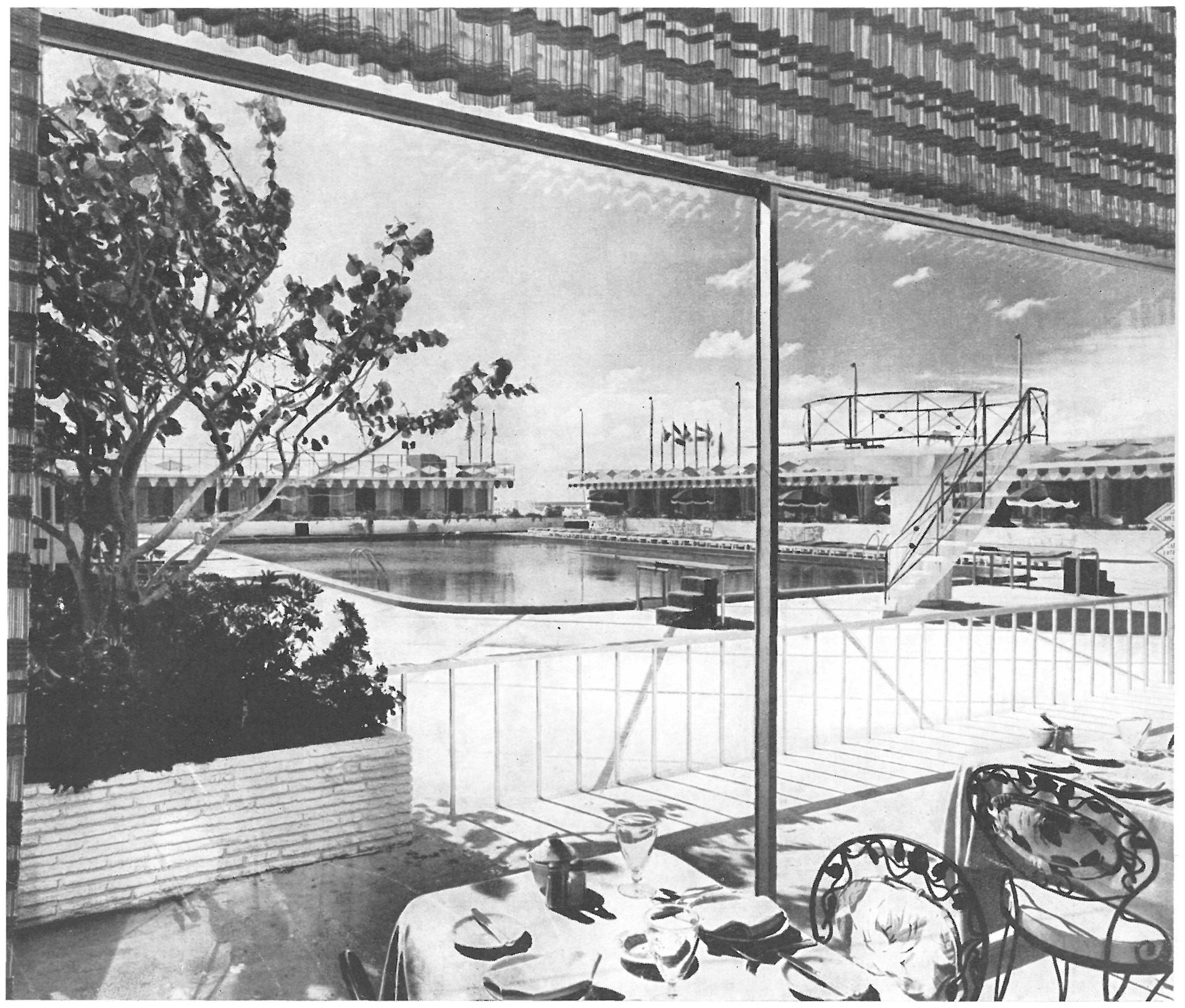

Un comedor al aire libre, el "Pavillon", complemento necesario a los servicios anteriormente citados en un hotel frente al mar, está decorado todo él con una traducción en hierro forjado de estilo veneciano. La mezcla de esta traducción, con visillos de traza veneciana de largas líneas horizontales, elementos decorativos de puro gusto norteamericano y otros nacidos del puro capricho del decorador, crean un ambiente extraño, muy luminoso por estar unido al exterior de la piscina visualmente a través de amplios ventanales.

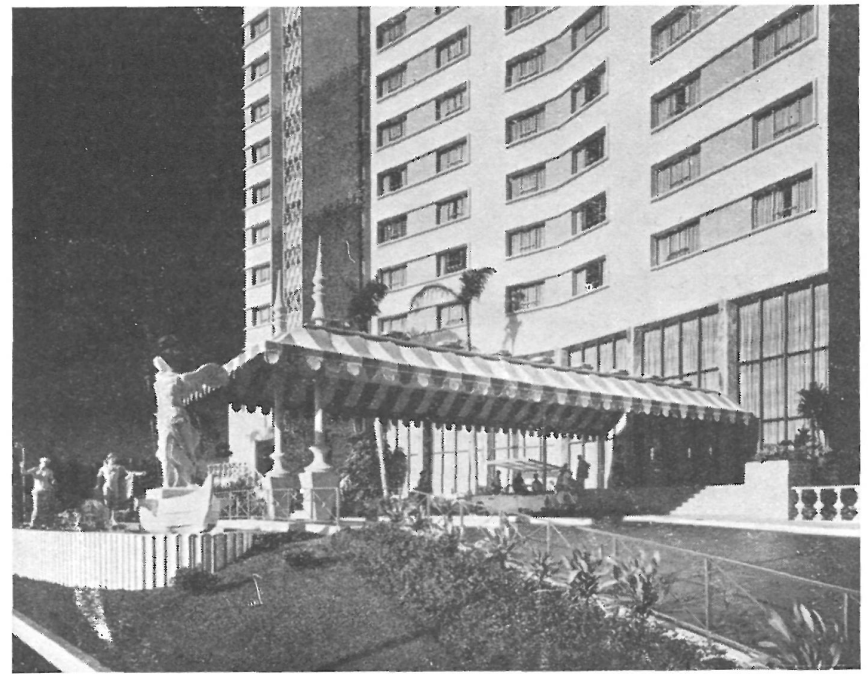



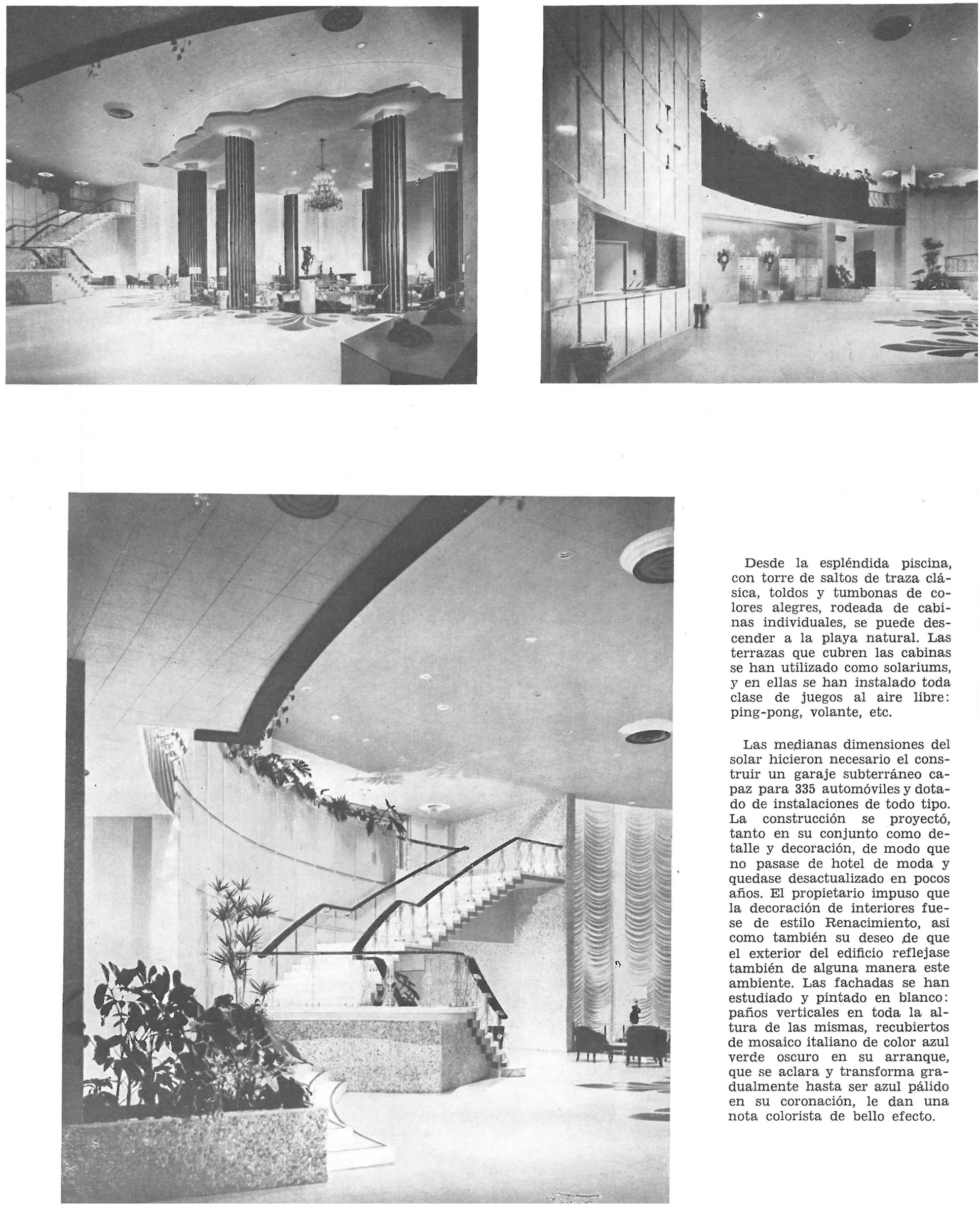

Desde la espléndida piscina, con torre de saltos de traza clásica, toldos y tumbonas de colores alegres, rodeada de cabinas individuales, se puede descender a la playa natural. Las terrazas que cubren las cabinas se han utilizado como solariums, $\mathrm{y}$ en ellas se han instalado toda clase de juegos al aire libre: ping-pong, volante, etc.

Las medianas dimensiones del solar hicieron necesario el construir un garaje subterráneo capaz para 335 automóviles y dotado de instalaciones de todo tipo. La construcción se proyectó, tanto en su conjunto como detalle y decoración, de modo que no pasase de hotel de moda y quedase desactualizado en pocos años. El propietario impuso que la decoración de interiores fuese de estilo Renacimiento, así como también su deseo de que el exterior del edificio reflejase también de alguna manera este ambiente. Las fachadas se han estudiado y pintado en blanco: paños verticales en toda la altura de las mismas, recubiertos de mosaico italiano de color azul verde oscuro en su arranque, que se aclara y transforma gradualmente hasta ser azul pálido en su coronación, le dan una nota colorista de bello efecto. 

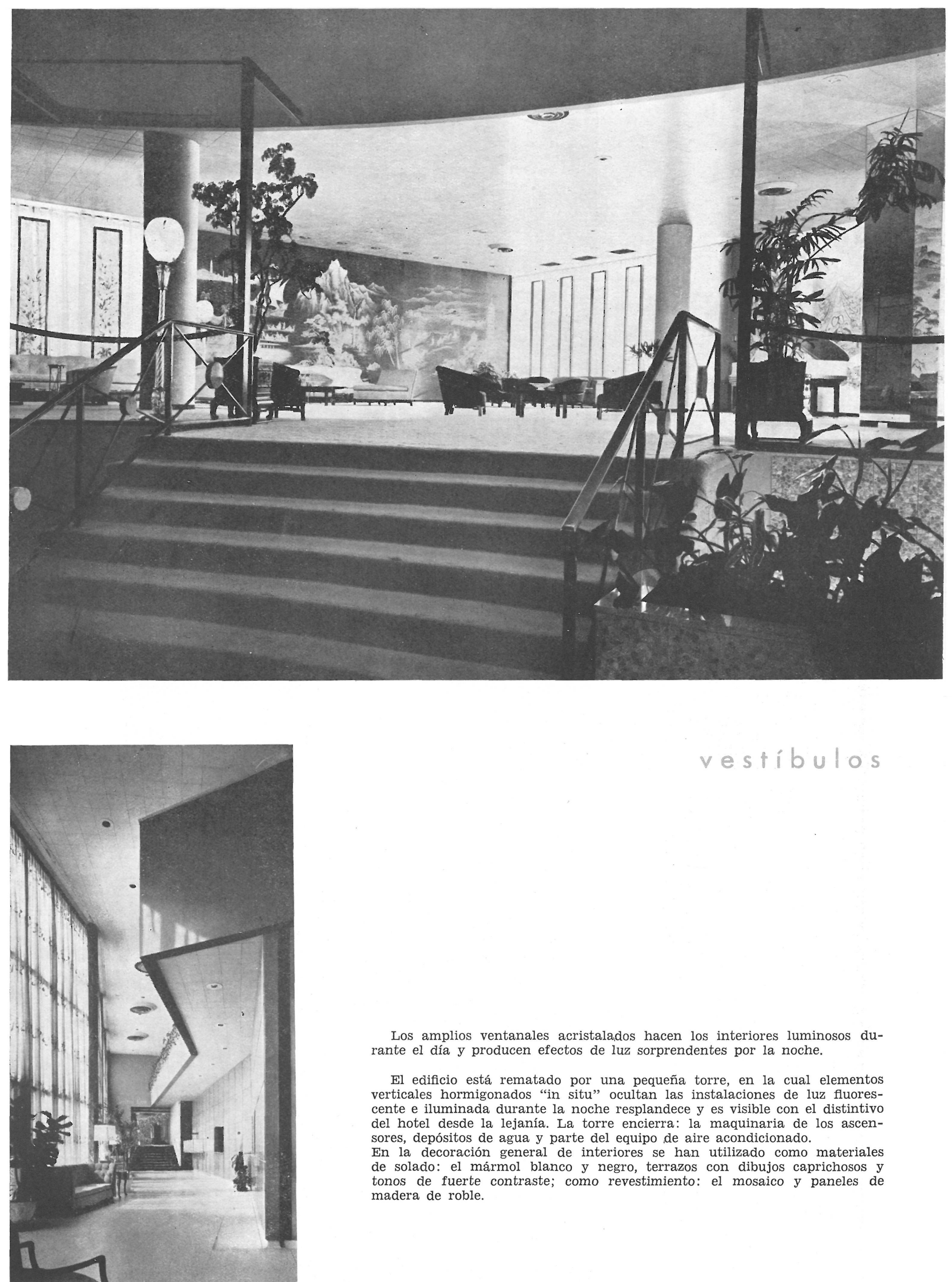

vestibulos

Los amplios ventanales acristalados hacen los interiores luminosos durante el día y producen efectos de luz sorprendentes por la noche.

El edificio está rematado por una pequeña torre, en la cual elementos verticales hormigonados "in situ" ocultan las instalaciones de luz fluorescente e iluminada durante la noche resplandece y es visible con el distintivo del hotel desde la lejanía. La torre encierra: la maquinaria de los ascensores, depósitos de agua y parte del equipo de aire acondicionado.

En la decoración general de interiores se han utilizado como materiales de solado: el mármol blanco y negro, terrazos con dibujos caprichosos y tonos de fuerte contraste; como revestimiento: el mosaico y paneles de madera de roble. 
bar y comedores

En el salón Marco Polo, un mural, pintado por un artista chino sobre seda, representa los viajes de este famoso personaje-en fondo rojo el de ida y en blanco el de vuelta-y es su principal motivo decorativo. Reproducciones de cuadros, dibujos arquitectónicos de Vignola, bronces y estatuas decoran los pasillos y complementan el deseado ambiente renacentista. Un suave juego de luces cambiantes presta al salón de baile ambientes variadísimos. Todas las habitaciones y "suites" están decoradas de manera diferente, si bien los tonos pastel predominan en todas ellas.

Toda la estructura es de hormigón armado. Unicamente en el forjado del hall principal y salón de baile se emplearon vigas de acero. El hotel está cimentado sobre pilotes, hincados por el procedimiento de inyección y calculados atendiendo más a la resistencia debida al rozamiento con el terreno que a la propia de los pilotes a la compresión. Para el sistema de aire acondicionado, que funciona por compresores refrigerados por agua, fué necesaria la perforación de varios pozos, ya que el caudal necesario era muy importante $y$, por tanto, suponía una sobrecarga peligrosa en las redes, por no estar lo suficientemente preparadas.

F. $M$.

«Harry's American Bar», "Comedor Pavillón", "Comedor Mona Lisa" y "Comedor Pompei».
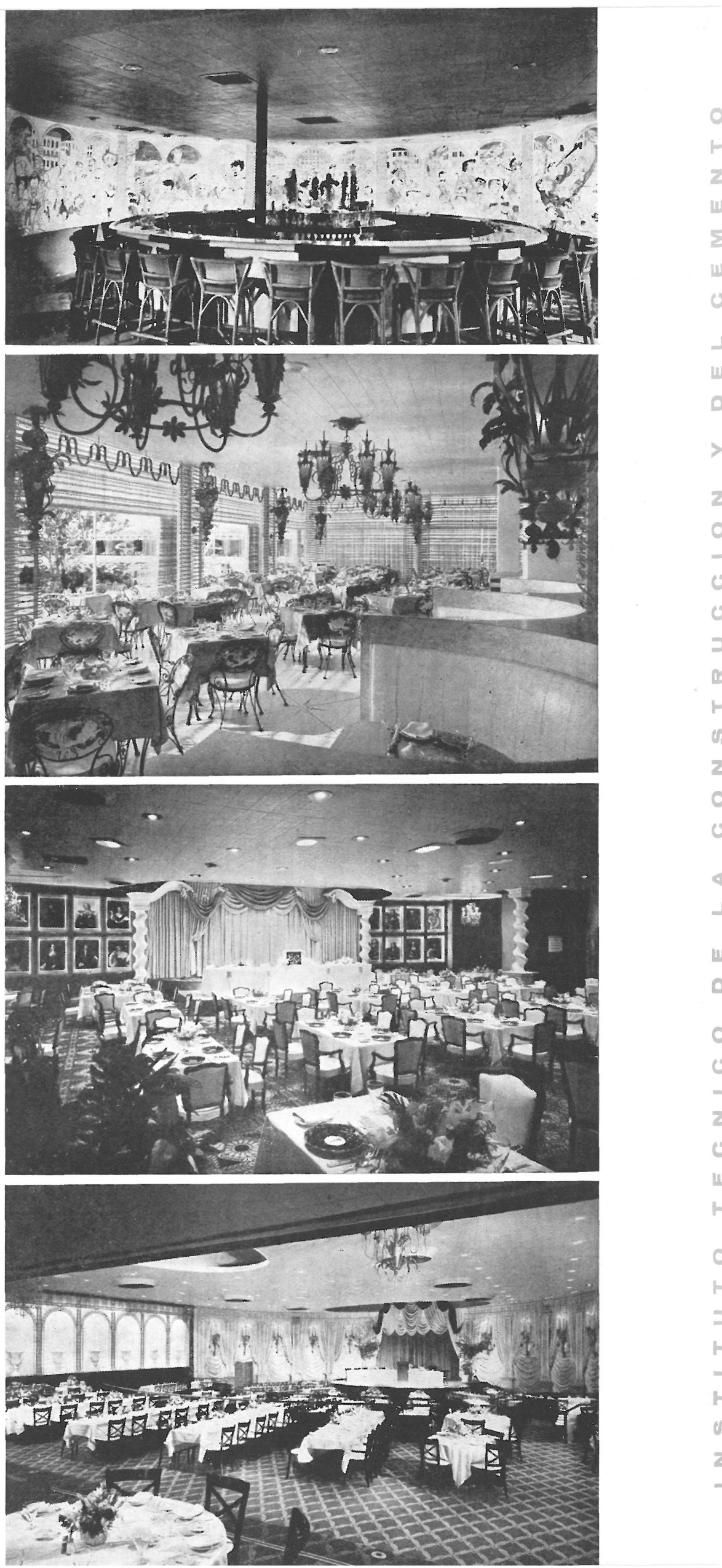